\title{
LEITURA, INTERPRETAÇÃO E PRODUÇÃO DE TIRINHAS: UMA EXPERIÊNCIA DE ESTÁGIO COM ALUNOS SURDOS DO ENSINO FUNDAMENTAL
}

\author{
Eva dos Reis Araújo Barbosa \\ Universidade Federal de Minas Gerais
}

\section{Resumo}

O Decreto no 5.626/2005 elege a Educação Bilíngue para alunos surdos, baseando-se na Libras como primeira língua (L1) e no Português como segunda língua (L2). Assim, surgem dificuldades quanto à: capacitação de professores; presença do intérprete na escola; adequação dos materiais e das avaliações. Este artigo visa defender a Educação Bilíngue e sugerir uma proposta de trabalho do Português por meio do gênero textual, tirinha. Este estudo foi realizado numa escola de Belo Horizonte/MG, cuja metodologia foi composta por: contato; leitura; interpretação e produção do gênero. Albres (2010); Bernardino (2000); Pereira (2003) e Quadros (1997) são referencias usadas para respaldar este estudo. Pode-se observar que o grande obstáculo dos alunos surdos está relacionado ao uso do Português escrito, já que eles não dominam suas estruturas sintáticas. Ressaltase também que, apesar de a Educação Bilíngue ser um direito respaldado por lei, ainda há muito a se fazer no Brasil nesta caminhada.

Palavras-chave: Educação de Surdos; Bilinguismo, Ensino de Português como Segunda Língua (L2); Gênero Textual Tirinha. 


\title{
READING, ANALYSIS AND PRODUCTION OF COMIC STRIPS: AN EXPERIENCE OF INTERNSHIP WITH DEAF STUDENTS OF ELEMENTARY EDUCATION
}

\begin{abstract}
Decree No. 5.626/2005 determines Bilingual Education for deaf students, based on Libras as first language (L1) and Portuguese as second language (L2). Therefore, some difficulties arise regarding: teacher training; presence of the interpreter in school; suitability of materials and tests. This paper aims to defend the Bilingual Education and suggest a work proposal for Portuguese using a type of text, called comic strips. This study was conducted in a school in Belo Horizonte/MG, and methodology used was: contact, reading, interpretation and production of comic strips. Albres (2010); Bernardino (2000), Pereira (2003) and Tables (1997) references are used to support this study. It can be observed that the major obstacle of deaf students is related to the use of written Portuguese, since they do not dominate their syntactic structures. We also emphasize that, although the Bilingual Education is a right by law, there is still much to be done in Brazil on this journey.
\end{abstract}

Keywords: Deaf Education; Bilingualism; Teaching Portuguese as a Second Language (L2); Textual Genre Comic Strips. 


\section{Introdução}

"O respeito à diferença linguística do surdo lhe é garantido só e se a educação é feita em sua língua natural. Todos os cidadãos devem ter o direito de ser educados em sua própria língua." (HORNENBERGER, 1998) ${ }^{1}$

A Educação de Surdos no Brasil é um tema bastante discutido por estudiosos da área das Línguas de Sinais. Essa preocupação se intensificou a partir da publicação do Decreto $n^{0} 5.626$, em dezembro de 2005, que defende a proposta do bilinguismo para o ensino de crianças surdas. Porém, mesmo com a discussão da eficácia da educação bilíngue para surdos, em 2012, o governo federal fechou várias escolas especiais no país e incluiu esses alunos em escolas regulares, o que requer a contratação de professores devidamente capacitados, a presença do intérprete nas salas de aula e a adequação dos materiais didáticos e dos métodos de avaliação, medidas que nem sempre são tomadas pelas escolas. Dentro desse novo quadro na Educação de Surdos, surge a dificuldade dos professores de Português no ensino da língua portuguesa como segunda língua, por falta de conhecimentos sobre as especificidades linguísticas e educativas dos alunos surdos, de capacitação para desenvolverem tal tarefa e de ambiente favorável para isso, já que estes professores devem lidar com diferentes tipos de alunos em uma mesma sala de aula.

O presente artigo possui como principal objetivo contribuir para a defesa da educação bilíngue para alunos surdos como sendo a mais adequada, visto que ela proporciona um melhor desenvolvimento cognitivo, social e afetivo. Além disso, oferece uma ideia de trabalho didático com um gênero textual, apresentando uma experiência que foi vivida, de fato, em uma sala de aula composta por alunos surdos.

Para dar embasamento às ideias expostas, foram escolhidos alguns teóricos da área da Libras e da Educação de Surdos, tais como Albres (2010); Bernardino (2000); Pereira (2003); Quadros (1997), e de outras áreas necessárias para a exposição do conteúdo, sendo consultados livros, artigos e documentos encontrados na internet.

\footnotetext{
${ }^{1}$ A epígrafe foi citada por Gesser (2009).
} 
O artigo é subdivido em três seções. A primeira seção apresenta, de maneira sucinta, um panorama da Educação de Surdos no Brasil, desde a criação da primeira escola, até a nova proposta de inclusão dos alunos surdos nas escolas regulares. A segunda seção discute quais são os principais obstáculos enfrentados pelos professores ao ensinarem a língua portuguesa como segunda língua para alunos surdos e propõe algumas atitudes que podem ser tomadas para amenizar tal situação. Na última seção, é apresentado um Projeto de Estágio que foi aplicado em uma escola especializada na Educação de Surdos, utilizando o gênero tirinha, na qual se explica a metodologia utilizada e há a discussão dos resultados obtidos.

\section{A educação de surdos no Brasil}

A Educação de Surdos no Brasil iniciou através da fundação da primeira escola de surdos - Imperial Instituto dos Surdos-Mudos²- no Rio de Janeiro, em 1857. A iniciativa dessa criação foi tomada pelo Imperador D. Pedro II que, para professor, convidou o francês Ernest Huet, que era surdo e utilizava a Língua de Sinais Francesa (ALBRES, 2010). Segundo Abbud \& Almeida (1998 apud ALBRES, 2010, p. 16), “[...] o professor francês, Ernest Huet, também era surdo, por isso acreditava na capacidade educacional das pessoas surdas". Assim, ele inaugurou o processo educacional dos surdos brasileiros e contribuiu para a formação da Língua de Sinais Brasileira (Libras) ${ }^{3}$.

A partir de então, a Educação de Surdos no Brasil seguiu basicamente os métodos utilizados nos demais países e sofreu forte influência da Europa (VILELA, s.d.). Um exemplo disso pode ser visto através do Congresso Internacional de Ensino de Surdos, que ocorreu em Milão, em 1880, no qual, através de uma votação, o oralismo foi escolhido como o método que deveria ser utilizado na Educação de Surdos, e o uso da Língua de Sinais foi oficialmente proibido nas escolas e nas casas de crianças surdas (ALBRES, 2010). Assim, segundo Villela (s.d., p.1):

\footnotetext{
${ }^{2}$ Atualmente o Instituto de Surdos é denominado INES - Instituto Nacional de Educação de Surdos.

${ }^{3}$ A Libras, que é uma língua de modalidade espaço-visual, “originou-se de outra língua de modalidade gestual-visual, a Língua de Sinais Francesa, apesar de a Língua Portuguesa ter influenciado diretamente a construção lexical desta Língua de Sinais, mas apenas por meio de adaptações, pois são línguas em contato" (ALBRES, 2010, p. 11).

Olh@res, Guarulhos, v. 2, n. 1, p. 345-372. Maio, 2014.
} 
[...] em 1911, o Instituto Nacional de Surdos (INES) passou a seguir a tendência mundial, utilizando o oralismo puro em suas salas de aula. Todavia, o uso dos sinais permanece até 1957, momento em que a proibição é dada como oficial.

O oralismo ou filosofia oralista, defende que o surdo deve desenvolver habilidades de fala, leitura orofacial e escrita, para que, dessa forma, ele seja incluído na sociedade ouvinte (ALBRES, 2010). Assim, ele busca uma "recuperação" da pessoa surda, que é denominada como "deficiente auditiva" (BERNARDINO, 2000, p. 29). Segundo Albres (2010), quando essa filosofia foi implementada na Educação de Surdos do Brasil, a Língua de Sinais foi denominada como sendo uma simples mímica e foi alvo de grandes críticas:

[...] considerada reducionista e perigosa. Apresenta-se ainda de forma simplificada e com erros gramaticais; além de transmitir apenas expressões concretas, reafirma a concepção de língua como um sistema com regras determinadas. Desse modo, a proposta do oralismo se fortalece (ALBRES, 2010, p. 26-27).

Outra filosofia presente na Educação de Surdos é a Comunicação Total ou bimodalismo, que chegou ao Brasil no início da década de 80 e foi adotada por algumas escolas, iniciando no país uma discussão a respeito de outros meios de comunicação para com os surdos, que não os métodos orais (ALBRES, 2010). Dentre os meios de comunicação defendidos podem ser citadas a língua-espaço visual, a datilologia, a língua oral etc. (POKER, s.d.). Porém, esse método que passou a ser defendido como "a melhor alternativa de ensino para o surdo" (QUADROS, 1997, p. 24) é bastante criticado por estudiosos, já que:

Na Comunicação Total usa-se o Português Sinalizado, que emprega sinais oriundos da LIBRAS (léxico) na gramática do português, usando simultaneamente a fala e os sinais [...] esse sistema inviabiliza o uso adequado da língua de sinais, pois seus itens lexicais, sua sintaxe, semântica e morfologia usam constantemente expressões faciais e movimentos da boca incompatíveis com a pronúncia simultânea das palavras da língua oral (BERNARDINO, 2000, p. 32).

A partir da Comunicação Total que, inicialmente, visava que as línguas de sinais fossem reconhecidas como um direito das pessoas surdas, foi criada uma nova filosofia para a Educação de Surdos, o bilinguismo, propondo que as línguas de sinais e as orais oficiais se tornem acessíveis ao surdo em seu contexto escolar 
(BERNARDINO, 2000). O bilinguismo começou a ser adotado no Brasil a partir dos anos 90 e, segundo Bernardino (2000, p. 29-30):

O Bilinguismo considera que a língua oral não preenche todas essas funções [de suporte do pensamento e de estimulador do desenvolvimento cognitivo e social], sendo imprescindível o aprendizado de uma língua visual-sinalizada desde tenra idade, possibilitando ao surdo o preenchimento das funções linguísticas que a língua oral não preenche. Assim, as línguas de Sinais são tanto o objetivo quanto o facilitador do aprendizado em geral, assim como do aprendizado da língua oral.

Após a divulgação do bilinguismo no Brasil, foram criadas escolas especiais, mistas ou somente de surdos, com a presença de intérpretes de Libras para ajudar no trabalho do professor em sala de aula (RODRIGUES, 2008). Após muitos anos de intensa luta, os surdos brasileiros tiveram sua língua reconhecida, através da publicação da Lei ${ }^{\circ} 10.436$, no ano de 2002, que diz o seguinte:

Art. $1^{\circ}$. É reconhecida como meio legal de comunicação e expressão a Língua Brasileira de Sinais - Libras e outros recursos de expressão a ela associados.

Parágrafo único. Entende-se como Língua Brasileira de Sinais - Libras a forma de comunicação e expressão, em que o sistema lingüístico de natureza visual-motora, com estrutura gramatical própria, constituem um sistema lingüístico de transmissão de idéias e fatos, oriundos de comunidades de pessoas surdas do Brasil (BRASIL, 2002, p. 1).

Alguns anos após a publicação dessa lei foi sancionado o Decreto $\mathrm{n}^{\mathrm{o}} 5.626$, em dezembro de 2005, que traz obrigações importantes em relação à Língua de Sinais dos surdos brasileiros, tais como: a inclusão da disciplina de Libras em todos os cursos de formação de professores e de Fonoaudiologia; a formação de docentes, instrutores e tradutores intérpretes de Libras; o direito à saúde pelas pessoas surdas e a difusão da Libras que deve ser feita nos setores públicos da sociedade brasileira.

Apesar das intensas discussões a respeito da eficácia do bilinguismo na educação de alunos surdos, em 2012, o governo federal, juntamente com o Ministério da Educação (MEC), optou por fechar várias escolas especiais no país. Este fato gerou um enorme desconforto na Comunidade Surda, que se uniu contra essa iniciativa que "prevê que os alunos sejam todos matriculados nas escolas regulares e que recebam atendimento especializado em outro horário" 4.

\footnotetext{
4 Informação extraída de uma notícia da internet sua fonte se encontra disponível das referências bibliográficas.

Olh@res, Guarulhos, v. 2, n. 1, p. 345-372. Maio, 2014.
} 
Essa nova política de inclusão apresenta vários obstáculos, já que é impossível implementar a proposta da educação bilíngue para alunos surdos dentro das escolas regulares, visto que não existem métodos e procedimentos de ensino eficazes para levar o aluno surdo a alcançar um bom desenvolvimento em sua produção de leitura e escrita (ALBRES, 2010). Segundo Albres (2010, p. 63):

\begin{abstract}
A inclusão e a acessibilidade dos surdos à educação não se resumem a inseri-los em uma escola de alunos ouvintes; e, quando possível, contratar um intérprete de Libras. Há também as adaptações dos interlocutores no espaço físico, dos materiais, das estratégias em sala de aula, assim como formação continuada dos professores, contratação de professores especializados [...], organização do horário para a realização das atividades complementares com o professor especializado, aquisição de recursos, projetos que envolvem a comunidade escolar.
\end{abstract}

Atualmente, algumas escolas especiais de Educação de Surdos ainda continuam abertas, através da luta da comunidade surda e de doações de terceiros, já que o governo federal, após instituir a inclusão, não oferece mais ajuda. O que se pode perceber nessas escolas é que as práticas pedagógicas utilizam tanto métodos e técnicas oralistas e da Comunicação Total, quanto o bilinguismo (ALBRES, 2010).

\title{
3. Ensino de português como segunda língua para alunos surdos
}

De acordo com o Decreto $\mathrm{n}^{\circ}$ 5.626, de dezembro de 2005, as instituições federais de ensino devem garantir a inclusão educacional dos alunos surdos em escolas bilíngues ou escolas comuns da rede regular de ensino abertas a alunos surdos e ouvintes, e estabelece que:

$\S$ 1o São denominadas escolas ou classes de educação bilíngue aquelas em que a Libras e a modalidade escrita da Língua Portuguesa sejam línguas de instrução utilizadas no desenvolvimento de todo o processo educativo (BRASIL, decreto $n^{\circ} 5.626,2005$ ).

Além da modalidade escrita da língua portuguesa, o decreto também prevê que haja a oferta da modalidade oral "preferencialmente em turno distinto ao da escolarização, por meio de ações integradas entre as áreas da saúde e da educação, 
resguardado o direito de opção da família ou do próprio aluno por essa modalidade" (BRASIL, decreto $n^{0}$ 5.626, 2005).

Diante desse paradigma na Educação de Surdos, no qual as escolas especiais estão sendo fechadas (apesar de serem um direito decretado) e os alunos surdos estão sendo incluídos nas escolas regulares, os professores encontram diversas dificuldades ao ensinar a Língua Portuguesa, já que este trabalho específico com alunos surdos requer um professor bilíngue, que domine a Libras e a Língua Portuguesa (ALBRES, 2010).

O maior obstáculo encontrado pelos professores é a dificuldade que os alunos surdos apresentam na leitura e na escrita do Português. As causas dessa dificuldade são explicadas por Albres (2010, p. 151-154):

- a Língua Portuguesa escrita é um sistema alfabético e representa a produção oral da Língua Portuguesa. Como as crianças que não ouvem não desenvolvem essa língua naturalmente, não têm esse elo para representá-la na escrita;

- as crianças surdas, em muitos casos, pouco ou nada conhecem de Língua Portuguesa oral, ou apenas dominam a Língua de Sinais, uma língua de modalidade gestual-visual, que não serve de ponte para a apropriação da Língua Portuguesa escrita com uso de metodologias tradicionais de alfabetização;

- os surdos não são alfabetizados na forma escrita de uma primeira língua e, assim, não podem fazer uso intuitivo das propriedades fonológicas naturais de sua fala interna em auxílio à leitura e escrita.

Uma sugestão para amenizar essa situação enfrentada pelos professores é dada pela mesma autora, que afirma que a Língua de Sinais tem um papel fundamental para o desenvolvimento cognitivo das crianças surdas, já que ela utiliza um canal de comunicação de fácil acesso a esses alunos. Assim, o professor pode utilizar a Libras para levar seus alunos surdos a compreenderem a Língua Portuguesa escrita (ALBRES, 2010).

Quadros (1997, p. 30) afirma, contudo, que "o domínio da língua nativa, apesar de ser essencial, não garante o acesso a uma segunda língua”, já que há vários fatores que determinam esse processo. Sendo assim, o que deve ser feito é investir na qualificação dos professores, conforme afirma Albres (2010, p. 9):

[...] uma vez que a escola comum também está incumbida, pela política inclusiva, dessa árdua tarefa, cabe fornecer informações aos professores sobre as necessidades educacionais especiais do alunado com surdez.

Olh@res, Guarulhos, v. 2, n. 1, p. 345-372. Maio, 2014. 
Esse tipo de capacitação também é prevista no decreto de dezembro de 2005, ao dizer que "deve ser proporcionado aos professores a literatura e informações sobre a especificidade linguística do aluno surdo" (BRASIL, decreto $\mathrm{n}^{\mathrm{o}} 5.626,2005$ ). O que se espera é que essas intenções sejam realmente colocadas em prática para que o aluno surdo possa ser verdadeiramente incluído na educação e possa se desenvolver bem em seus âmbitos cognitivos, afetivos e sociais.

\section{Produção de tirinhas por alunos surdos: o desafio}

O Projeto de Estágio de leitura, interpretação e produção de tirinhas por alunos surdos foi realizado durante o primeiro semestre de 2013, para a disciplina Análise da Prática e Estágio do Português I, que é obrigatória para a formação acadêmica dos graduandos do curso de Letras, da Universidade Federal de Minas Gerais. A partir da observação das aulas de Português, em uma escola de Ensino Fundamental II, os alunos deveriam criar um Projeto de Ensino e aplicá-lo, tendo em vista as orientações da supervisora do estágio ${ }^{5}$.

O projeto em questão foi aplicado em uma escola especializada em Educação de Surdos, que atende alunos de toda a região metropolitana de Belo Horizonte. ${ }^{6}$ A escola é filantrópica, de cunho religioso e foi fundada na década de 40, sendo uma das precursoras da Educação de Surdos em Minas Gerais. A partir da observação das aulas e do funcionamento da escola feita pela aluna estagiária, foi possível perceber que a escola encontra-se em um período de transição entre o método de ensino oralista e a Educação Bilíngue, utilizando, muitas vezes, técnicas da Comunicação Total, com o uso de todas as formas possíveis de comunicação para com os alunos surdos: fala, escrita, sinais, gestos, português sinalizado ${ }^{7}$, etc. Dessa forma, há a confirmação do que foi dito por Albres (2010), ao observar que as práticas pedagógicas ainda não estão bem definidas nas escolas que recebem alunos surdos.

\footnotetext{
${ }^{5}$ Considera-se como supervisora de estágio a professora responsável pelas aulas de português na escola escolhida como campo de estágio.

${ }^{6}$ Por questões de privacidade decidiu-se não mencionar o nome da escola, bem como dos participantes da aplicação do projeto de estágio.

${ }^{7}$ Segundo Quadros (1997), o português sinalizado diz respeito ao uso dos sinais dentro da estrutura da língua portuguesa.

Olh@res, Guarulhos, v. 2, n. 1, p. 345-372. Maio, 2014.
} 
Os objetivos desse projeto eram: caracterizar o gênero tirinha utilizando vários recursos ilustrativos; desenvolver o método de compreensão das historinhas através da Libras; estimular a aprendizagem da leitura e da escrita através da língua portuguesa; incentivar o gosto pela leitura ao propiciar a interação entre a Libras e a língua portuguesa nesse processo; trabalhar a criatividade e a imaginação dos alunos através de uma atividade de criação de suas próprias tirinhas e explorar a leitura de imagens. A constituição desse Projeto de Estágio é mais bem explicada nas próximas seções.

\subsection{A escolha do gênero}

Para a realização do Projeto de Estágio foi escolhido o trabalho com o gênero textual tirinha. De acordo com Mendonça (2005 apud BRITO; ELIAS, 2011, p. 6), as tirinhas são:

[...] uma subdivisão das HQs; com histórias mais curtas que facilitam e agilizam a leitura dos textos, podendo ser sequenciadas com narrativas mais longas ou fechadas (um episódio por vez). A temática presente na maioria das tiras é a sátira, elas normalmente satirizam aspectos políticos e econômicos do país.

Além disso, as tirinhas se enquadram no tipo textual narrativo, já que possuem personagens, enredo e acontecem em um determinado lugar, circulando no meio midiático, em jornais, revistas, internet etc. (MOTENARI, MENEGASSI, 2010). A escolha desse gênero textual se justifica pela observação das aulas no campo de estágio, na qual foi percebido que a professora possuía muitas dificuldades em encontrar textos que fossem compatíveis com a faixa etária e a série em que os alunos se encontravam, já que eles possuíam um vocabulário reduzido em relação ao Português e tinham interesses diversos daqueles que eram tratados nos textos com vocabulário mais simples, já que estes eram considerados pelos alunos como sendo infantis. Portanto, foi preciso pensar em um gênero em que os alunos tivessem menos dificuldades de leitura e mais interesse, e as tirinhas se encaixaram perfeitamente, uma vez que, segundo Montenari e Menegassi (2010, p. 4): 
[...] as tiras em quadrinhos podem ser utilizadas em sala de aula e em qualquer nível de ensino, pois são inúmeros os temas e finalidades, delineados por diferentes estilos linguísticos. Além disso, esse gênero discursivo é de fácil acesso e chama a atenção de muitos leitores de diversas idades visto que o visual e o verbal, em um jogo interativo, são ótimos recursos para que se desperte a autonomia, o lado crítico do aluno e, consequentemente, o domínio da Língua Portuguesa.

Outro fator que serviu como auxílio durante a escolha do gênero foi a possibilidade de se trabalhar com a imagem. Segundo Silva (2010), a imagem facilita a interação entre o professor e os alunos surdos, já que ela ajuda a preencher algumas lacunas que possam aparecer durante a comunicação e é uma ferramenta importante que contribui para a ampliação do conhecimento de mundo desses alunos. Dessa forma, a imagem se apresenta como algo essencial na Educação de Surdos, já que, segundo Vieira e Araújo (2012), ela auxilia na compreensão textual do surdo, servindo como uma estratégia de préconhecimento, ao ser utilizada como referência para a construção de sentido do conteúdo verbal. Além disso, ela se torna um recurso para a aprendizagem da língua portuguesa.

\subsection{Metodologia}

Esse projeto foi aplicado em dois horários de aula de 50 minutos, em uma turma de 09 alunos surdos da $6^{\text {a }}$ série. Foi levado em conta o método de ensino da professora, que utilizava, de maneira interativa, a Libras e a Língua Portuguesa, o que facilitava o processo de interpretação e compreensão de textos pelos alunos surdos.

Essa proposta de aula foi composta por quatro passos principais: primeiro contato com o gênero, leitura do gênero, exercícios de interpretação e produção do gênero. Os passos utilizados serão explicitados a seguir. 


\subsubsection{Primeiro contato com o gênero}

Na primeira etapa de aplicação do Projeto, a professora estagiária ${ }^{8}$ apresentou aos alunos uma revistinha em quadrinhos da Turma da Mônica, de Maurício de Souza, sem mencionar ainda o conceito de tirinha, a fim de descobrir o que os alunos já conheciam a respeito do gênero em questão. Vale ressaltar que essa primeira intervenção foi realizada pela professora estagiária usando somente a Libras como meio de comunicação. Após apresentar a revistinha para a turma foram feitas as seguintes perguntas aos alunos:

\section{Quadro 1 - Primeiro grupo de perguntas}

1 - Alguém sabe o que é isto que eu trouxe para a aula de hoje?

2 - Quem gosta de ler este tipo de revista?

3 - Vocês gostam de ler histórias em quadrinhos? Quais historinhas vocês leem?

4 - Para que servem os quadrinhos?

Fonte: a autora.

Após o primeiro contato com o conhecimento dos alunos sobre o gênero história em quadrinhos, levando em consideração suas respostas às perguntas iniciais, foi mostrada uma tirinha da mesma revistinha (as tirinhas, geralmente, vêm no final dos gibis e das revistas de histórias em quadrinhos), fazendo as seguintes perguntas:

\section{Quadro 2 - Segundo grupo de perguntas}

$$
1 \text { - E isto, o que é? }
$$

2 - Elas são diferentes das histórias em quadrinhos desta revista? Por quê?

3 - Onde podemos encontrar este tipo de historinha?

Fonte: a autora.

Através das respostas dos alunos a este segundo grupo de perguntas foi realizada uma breve explicação a respeito da diferença entre as histórias em quadrinhos e as tirinhas, mais uma vez, utilizando somente a Libras como meio de comunicação

\footnotetext{
${ }^{8}$ O Projeto de Estágio foi aplicado pela professora estagiária sob a supervisão da professora supervisora, que esteve presente na sala durante a aplicação, para apoiar e avaliar a prática docente da aluna de estágio.

Olh@res, Guarulhos, v. 2, n. 1, p. 345-372. Maio, 2014.
} 
com os alunos. Depois disso, foram apresentadas as principais características das tirinhas utilizando anotações de algumas informações no quadro negro e um handout (bem didático e com ilustrações), desta vez utilizando a língua portuguesa escrita, já que a escola não possui data-show e, portanto, não foi possível o uso de slides.

\subsubsection{Leitura do gênero}

O segundo passo constituiu na leitura do gênero em questão. Para isso, foram apresentadas diferentes tirinhas (da Turma da Mônica, do Calvin, da Mafalda e também algumas com temática de Libras) para que os alunos percebessem na prática as características do gênero que foram anteriormente explicitadas. As tirinhas foram levadas em uma caixa de sapato decorada, e cada aluno foi incentivado a escolher uma delas, tendo um tempo para lê-la, para posteriormente contá-la para seus colegas utilizando a Libras. Durante a leitura e a apresentação das tirinhas, houve a intervenção da professora estagiária para auxiliar o entendimento de algumas palavras que foram consideradas pelos alunos como sendo de difícil compreensão, dando seus significados em Libras.

\subsubsection{Exercícios de interpretação}

No terceiro momento, os alunos fizeram alguns exercícios de interpretação. Estes exercícios foram elaborados previamente pela estagiária a partir de algumas tirinhas escolhidas e sob a orientação da professora supervisora do estágio. Um dos objetivos dessas atividades era comprovar os conhecimentos adquiridos pelos alunos a respeito do gênero ensinado, além de testar sua compreensão utilizando o Português escrito, ou seja, sem o auxílio da Libras.

\subsubsection{Produção do gênero}

Um dos exercícios citados trazia instruções para a criação de uma tirinha que os alunos produziram em casa, tendo o prazo pré-estabelecido de uma semana para entregarem suas produções. A partir das tirinhas produzidas pelos alunos, foi 
composto um livrinho, que foi copiado e entregue para cada um deles. Este fato serviu como um incentivo para suas produções, visto que a criação teve como finalidade a divulgação do texto, não sendo apenas parte de um exercício avaliativo. Além disso, os alunos tiveram a oportunidade de ler as criações de seus colegas.

\subsection{Análises e discussões dos resultados}

Após a aplicação do Projeto, os resultados obtidos foram analisados através da apresentação do gênero, da leitura, da interpretação e da produção de tirinhas pelos alunos surdos. Estes resultados são descritos a seguir.

\subsubsection{Apresentação do gênero}

No primeiro passo, ao apresentar a revistinha para os alunos, eles reagiram bem e demonstraram já possuir algum conhecimento a respeito das histórias em quadrinhos. Em resposta ao primeiro grupo de perguntas, foi unânime que se tratava de uma revistinha em quadrinhos, que eles gostavam de ler e que as histórias preferidas eram da Turma da Mônica. Essa preferência pode ser devido ao fato de que, talvez, eles não conheçam, ou não saibam o nome, de outros personagens de tirinhas.

Em relação ao segundo grupo de perguntas, os alunos demonstraram não saber a diferença entre os quadrinhos e as tirinhas, apesar de a professora já ter trabalhado com eles esse tipo de gênero em outras aulas e atividades. Com relação ao local onde o gênero pode ser encontrado, eles responderam: revistinhas, jornais, internet e livros, evidenciando que já tiveram contato com o gênero e seus suportes em algum momento de suas vidas.

Todos os alunos copiaram as informações que foram passadas no quadro, não apresentando dificuldades na realização de tal tarefa. Durante a explicação do conteúdo passado no quadro e do conteúdo do handout, que foi realizada em Libras ${ }^{9}$, os alunos se mostraram atentos e interessados. Muitos já conheciam

\footnotetext{
${ }^{9}$ Essa atitude seguiu a sugestão de ALBRES (2010, p. 170): “[...] é necessário que toda mediação, orientação e explicação seja feita por meio da Libras".

Olh@res, Guarulhos, v. 2, n. 1, p. 345-372. Maio, 2014.
} 
algumas características do gênero, dizendo já terem visto algo sobre a representação da fala dos personagens em balões, o que facilitou muito a apresentação. A única palavra utilizada sobre a qual eles tiveram dúvida foi crítica, mas essa situação foi resolvida com a ajuda da professora supervisora que improvisou seu significado com outros sinais existentes na Libras.

Segundo Pereira (2003, p. 50): "a única forma de assegurar que os textos se tornem significativos para os alunos surdos é interpretá-los através da língua de sinais". Esse interesse pela aula evidencia a importância do uso da Libras para a explicação de conteúdos em Português, já que possibilita um melhor entendimento do conteúdo por parte dos alunos surdos.

\subsubsection{Leitura em Português e interpretação em Libras}

Com relação à segunda parte da aplicação do Projeto, os alunos gostaram muito da dinâmica realizada e se divertiram bastante. Isso comprova o que destaca Albres (2010, p. 170), ao dizer que, "para a construção de uma prática pedagógica, os professores devem procurar dinâmicas que estimulem as crianças, que ofereçam oportunidades para que elas interajam". Além disso, foram seguidas as sugestões da mesma autora ao afirmar que, durante as atividades realizadas em sala de aula, deve ser mesclado o uso do Português-por-escrito e a Libras (ALBRES, 2010).

Alguns alunos mostraram mais facilidade do que outros durante a atividade de leitura e no "reconto" em Libras, mas todos conseguiram, de alguma forma, transmitir o que estava sendo dito na tirinha aos seus colegas. O que se pôde observar é que, durante a interpretação das historinhas, os alunos utilizaram bastante seu conhecimento de mundo, trazendo para sua interpretação em Libras aquilo que eles já sabiam a respeito dos personagens e do gênero proposto. Segundo Pereira (2003), "para que leiam e escrevam, as crianças surdas, assim como todas as outras, necessitam ter conhecimento de mundo de forma que possa recontextualizar o escrito e daí derivar sentido".

Algumas situações interessantes também merecem destaque nesta seção: 
- ao "recontarem" as historinhas do personagem Calvin, os alunos se referiram a ele como sendo "um menino surdo". Eles começaram a contar a tirinha da seguinte maneira: “Um dia, um menino surdo...”. Isso talvez tenha ocorrido pelo fato de que os alunos não conheciam o personagem ou, porque, nas tirinhas em questão, não há a representação da fala do personagem, mas somente suas imagens, como é possível verificar a seguir

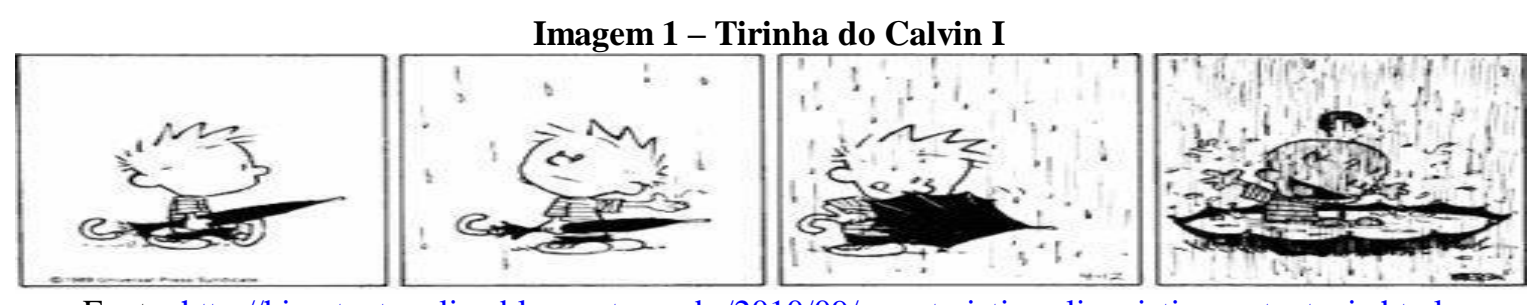

Fonte: http://hipertextoonline.blogspot.com.br/2010/09/caracteristicas-linguisticas-e-textuais.html.
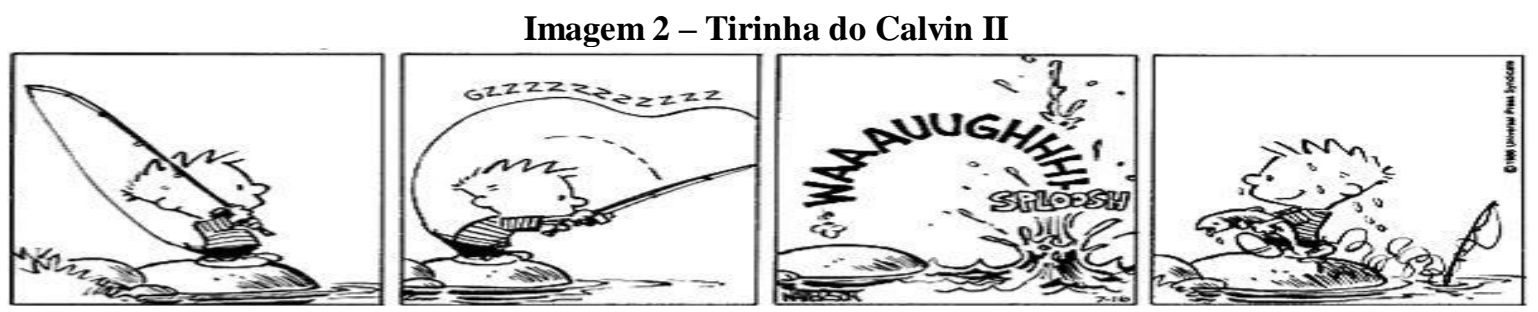

Fonte: https://extravirgem.wordpress.com/tag/calvin-e-haroldo/page/2/

- no entanto, esse mesmo fato não ocorreu durante a leitura de uma tirinha da Turma da Mônica (a imagem 3, por exemplo), que também não possui a fala dos personagens, mas estes já são conhecidos por todos os alunos e, inclusive, tal revistinha foi citada como sendo o tipo mais lido por todos.

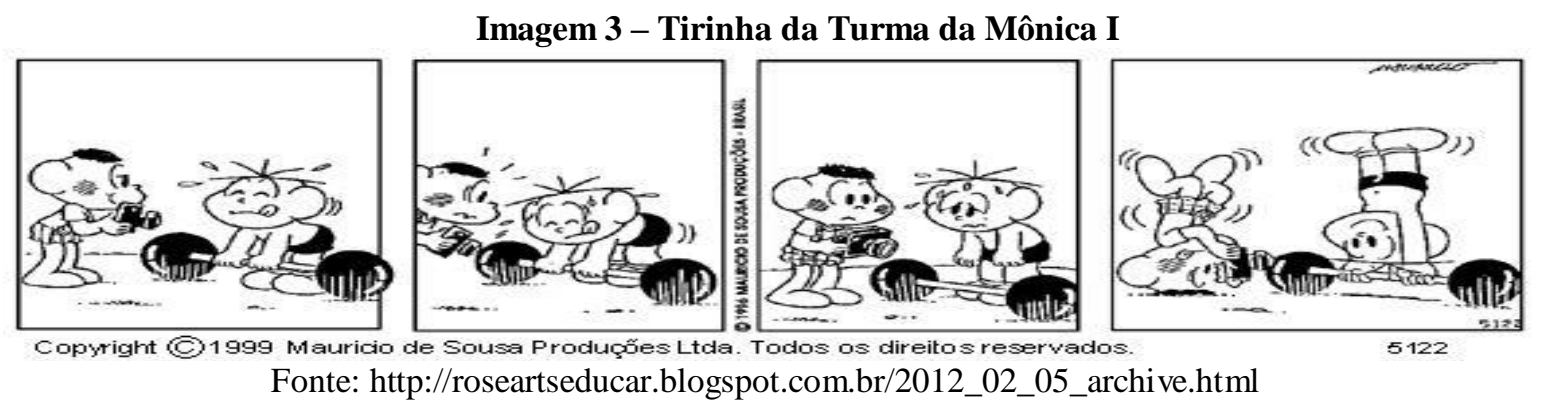

Olh@res, Guarulhos, v. 2, n. 1, p. 345-372. Maio, 2014. 
- $\quad$ somente duas palavras não foram compreendidas pelos surdos no momento da leitura e da interpretação: sensível e felicidade. No primeiro caso, o aluno pediu auxílio à professora supervisora (apesar de haver um sinal na Libras para essa palavra), que o ajudou, dando o significado a partir de outros sinais da Libras. No segundo caso, o aluno não pediu auxílio à professora supervisora ou à professora estagiária, mas demonstrou dificuldade na compreensão, uma vez que, apesar de a palavra possuir um sinal específico em Libras, ele utilizou o recurso da datilologia soletração manual ${ }^{10}$ para representá-la. Os dois casos demonstram uma falta de conhecimento não somente do vocabulário do Português, mas também dos sinais específicos da Libras. As tirinhas em questão estão apresentadas nas imagens 4 e 5.

\section{Imagem 4 - Tirinha de surdos I}
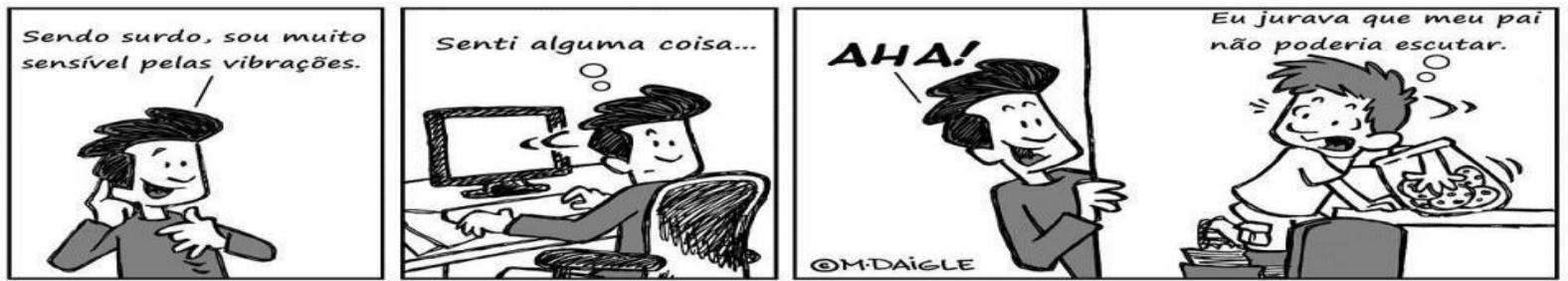

Fonte: https://www.facebook.com/photo.php?fbid=357039837661942\&set=pb.354521641247095.2207520000.1400501901.\&type $=3 \&$ theater

Imagem 5 - Tirinha da Mafalda I
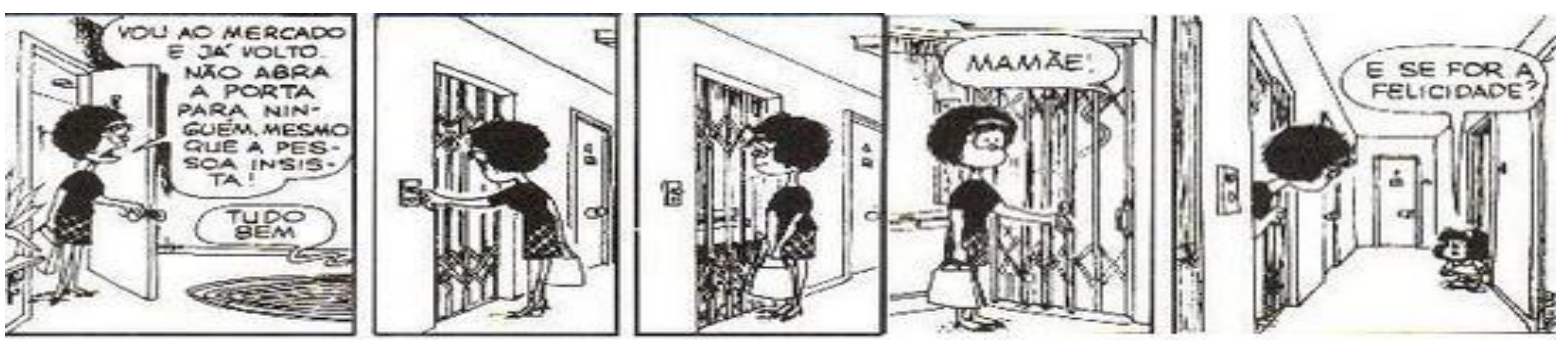

Fonte: http://sheusestangerines.wordpress.com/tag/tirinha-da-semana/

- os alunos ficaram muito satisfeitos ao saber que existem tirinhas com temática de surdos, Eles se mostraram curiosos e disseram que iriam pesquisar mais a respeito dessas tirinhas na internet.

\footnotetext{
10 "O alfabeto soletrado manualmente [...] é um conjunto de configurações de mão que representam o alfabeto do português.” (QUADROS; KARNOPP, 2004, p. 88).

Olh@res, Guarulhos, v. 2, n. 1, p. 345-372. Maio, 2014.
} 
Considera-se que os resultados obtidos nesse segundo momento foram bastante satisfatórios, já que se pensou que os alunos apresentariam uma dificuldade maior na realização de tal tarefa. Um fator que poderia ter sido mais bem explorado é a diversidade de interpretações de uma mesma tirinha por diferentes alunos utilizando a Libras, porém o projeto em questão não propôs a troca de tirinhas, já que o tempo de aula cedido para a aplicação não seria suficiente. A atividade proposta pela estagiária, na qual os alunos leram as tirinhas em Português, mas tiveram a oportunidade de "recontá-las" em Libras, serviu para evidenciar o importante papel que a língua de sinais possui no aprendizado e na compreensão da criança surda, uma vez que, segundo Pereira (2003, p. 49):

"é através dela que os alunos surdos poderão atribuir sentido ao que leem, deixando de ser meros decodificadores da escrita, e é através da comparação da língua de sinais com o português que irão constituindo o seu conhecimento do português".

\subsubsection{Interpretação escrita}

Durante a realização das atividades de interpretação escrita, as dificuldades encontradas pelos alunos foram bem maiores em comparação às atividades de leitura, principalmente porque, para realizá-las, foi necessário o uso da língua portuguesa escrita. Os resultados obtidos confirmam as dificuldades descritas por Fernandes (1990 apud Albres, 2010, p. 159), ao dizer que os maiores problemas encontrados pelos alunos surdos durante a escrita são a "dificuldade com o léxico e a falta de domínio das estruturas sintáticas da língua”. Alguns registros encontrados, exemplificados a seguir, dizem respeito à ortografia, ao uso das classes gramaticais e a aspectos semânticos e pragmáticos que podem ser diferenciados entre a Libras e o Português ${ }^{11}$ :

- Ortografia: Casção (Cascão), Cansção (Cascão), esta (está), dulex (durex), constuma (costuma), silencio (silêncio).

- Emprego dos pronomes: Me costumo ver só na revistinha. (Eu costumo ver só na revistinha.).

\footnotetext{
${ }^{11}$ Os escritos em itálico referem-se às respostas dadas pelos alunos e os que estão entre parênteses referem-se ao uso "correto" das palavras para o contexto das atividades.

Olh@res, Guarulhos, v. 2, n. 1, p. 345-372. Maio, 2014.
} 
- Emprego de artigos: Ele calou na boca do Casção com dulex. (Ele calou a boca do Cascão com o durex.) / Tampa na boca com a fita. (Tampa a boca com a fita.).

- Emprego de conectivos: Porque Mônica batendo o coelho e para a cabeça do Cebolinha. (Porque a Mônica está batendo o coelho na cabeça do Cebolinha.) / Está gritando que ele está durex na boca mais ele foi embora. (Está gritando que está com durex na boca, 또 mas ele foi embora.).

- Conjugação verbal: Cebolinha viu e correu para pegando a maleta de médico. (Cebolinha viu e correu para pegar a maleta de médico.) / Cascão chamar da mamãe. (Cascão chamou a mamãe).

- Significado de expressões: Os alunos não conseguiram escrever algumas expressões utilizadas na língua falada e escrita e, muitas vezes, sinalizaram a ação pedindo que a professora estagiária dissesse como escrevê-la em Libras. Ex: Calou na boca (calou a boca), tampou na boca (tampou a boca), foi correu (saiu correndo), está silêncio (ficou em silêncio), andar embora (foi embora), etc.

- Dificuldades de interpretação do enunciado: Muitos alunos não compreenderam bem o que o enunciado pedia. $\mathrm{O}$ enunciado que apresentou maiores dificuldades de interpretação perguntava o que os alunos achavam que havia acontecido depois do que é mostrado na tirinha, mas eles interpretaram como sendo o que aconteceu no último quadrinho. Um exemplo disso é indicado por meio das imagens 6 e 7.

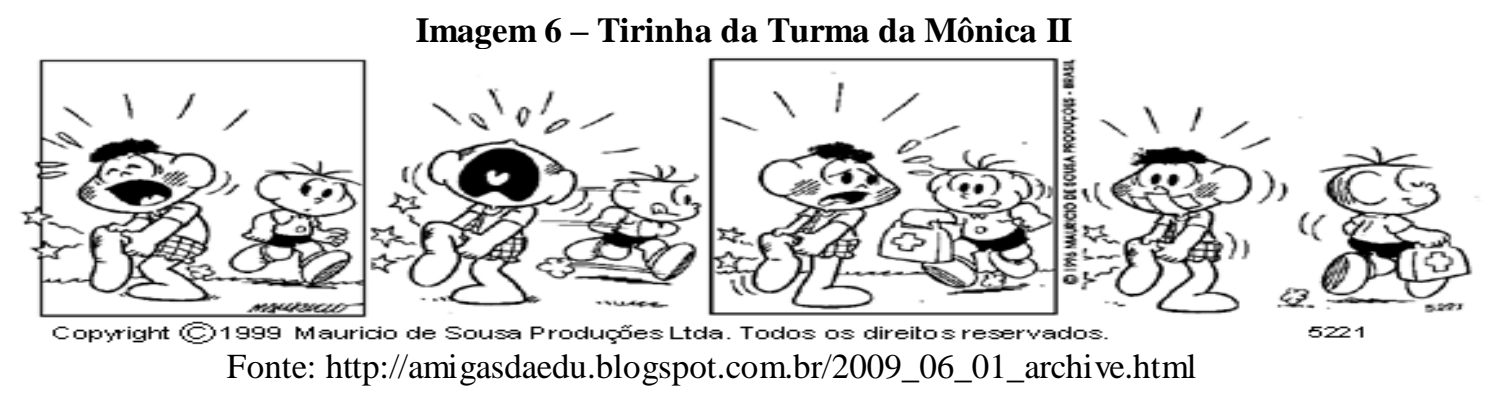

Olh@res, Guarulhos, v. 2, n. 1, p. 345-372. Maio, 2014. 
c) $O$ que você acha que aconteceu depois disso?

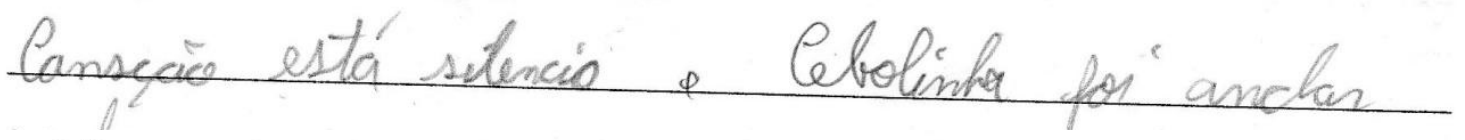

c) $O$ que você acha que aconteceu depois disso?

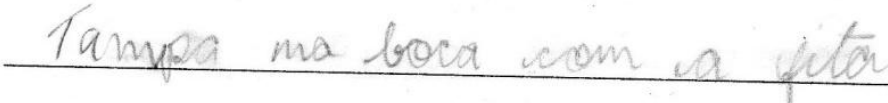

c) O que você acha que aconteceu depois disso?

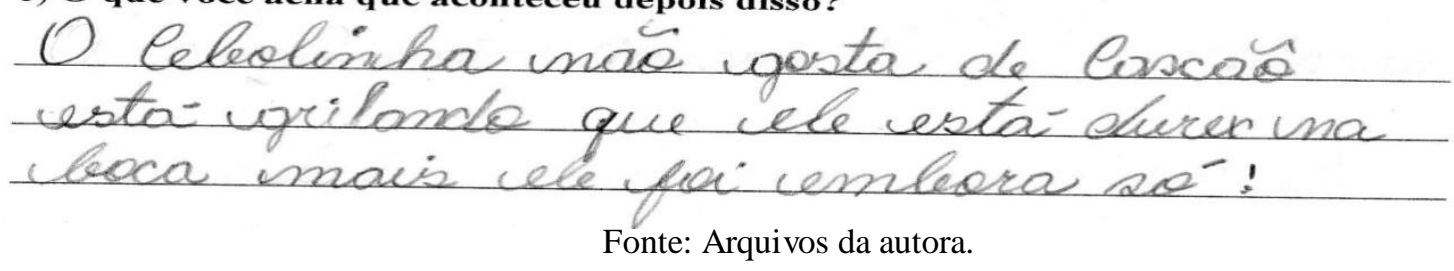

- Dificuldades na leitura de imagens: Em uma das tirinhas apresentadas, a Mônica pergunta ao Cebolinha por que ele não quer mais brincar de casinha. O Cebolinha, que está fazendo todo o serviço de casa na brincadeira, enquanto a Mônica é quem vai trabalhar, responde: “Adivinha!”. No enunciado da questão, os alunos deveriam dizer por que, na opinião deles, o Cebolinha não queria mais brincar. Porém, alguns inventaram a resposta (a partir do conhecimento que possuíam das histórias da Turma da Mônica) ou fizeram uma interpretação equivocada da questão, não conseguindo encontrar a resposta a partir das imagens, como é possível verificar nas imagens 8 e 9 .

\section{Imagem 8 - Tirinha da Turma da Mônica III}

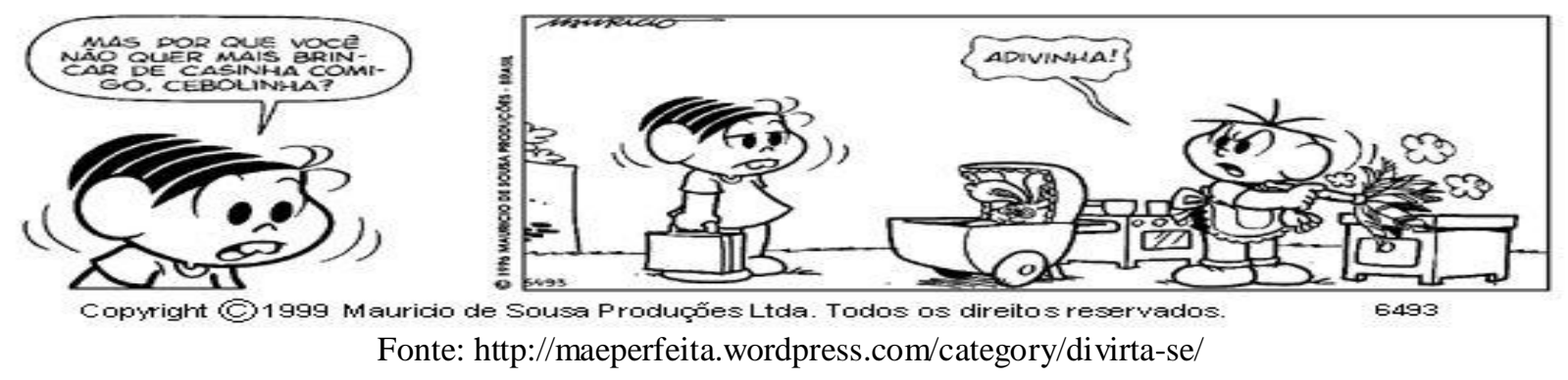

Olh@res, Guarulhos, v. 2, n. 1, p. 345-372. Maio, 2014. 


\section{Imagem 9 - Respostas dos alunos II}
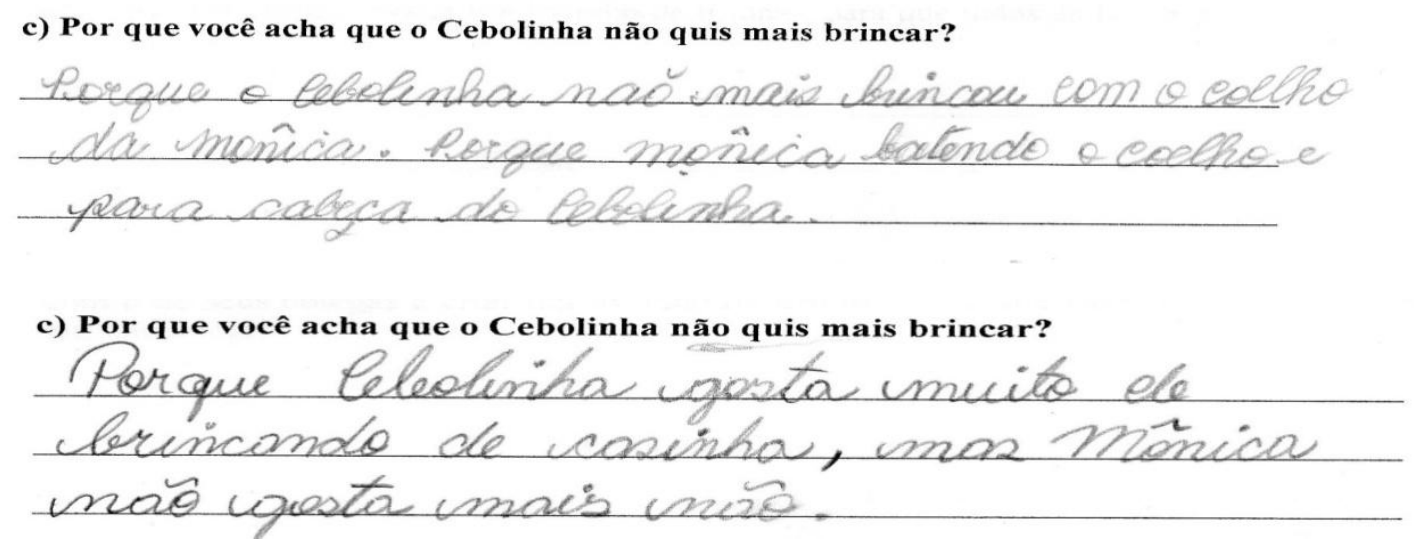

Fonte: Arquivos da autora.

Além disso, durante a realização dessas atividades em sala de aula, os alunos usaram frases curtas, quase não fizeram uso de vírgulas, solicitaram orientações constantes da professora estagiária com relação a algumas palavras presentes nos enunciados das questões e apresentaram a interferência da Libras ao escreverem suas respostas.

Essas características da escrita dos alunos surdos, muitas vezes, funcionam como um obstáculo na prática docente do professor, que se sente perdido em meio a várias dúvidas: Como corrigir as produções escritas dos meus alunos surdos? O que levar em conta durante a correção? Segundo Albres (2010, p. 164), é importante dar um retorno dos erros cometidos pelos alunos e pedir a reescrita dos textos, já que "pela interferência e dedução eles constroem hipóteses erradas de produção do Português como segunda língua, que se não forem corrigidas podem se cristalizar".

Essa dificuldade também foi encontrada pela professora estagiária no momento da avaliação das atividades realizadas pelos alunos, por ter dúvidas em qual ponto focar durante sua correção: a ortografia, a gramática ou a interpretação de texto. De acordo com Albres (2010, p. 165):

O que se tem feito diante desse quadro é ser mais brando na avaliação. Assim, de forma paliativa, o MEC orienta que os critérios para a avaliação devam ser diferenciados para alunos surdos. Por meio do Aviso Circular 27794 e da Portaria n ${ }^{\circ} 167999$, sugere a necessidade de se considerar, na Língua Portuguesa, o conteúdo em detrimento da forma. 
Após consultar uma professora de Libras da Faculdade de Letras/UFMG e ler a respeito do assunto, a professora estagiária optou por centrar sua correção na interpretação do texto feita pelos alunos. Não foi possível pedir a reescrita das atividades pelos alunos, pelo fato de que o tempo cedido para a aplicação do projeto não foi suficiente para tal ação.

\subsubsection{Produção}

A produção das tirinhas pelos alunos superou as expectativas da professora estagiária, já que eles demonstraram grande criatividade e facilidade na criação das histórias e dos desenhos. Poucos alunos utilizaram os recursos de representação das falas dos personagens em diferentes tipos de balões, conforme foi ensinado na parte expositiva da aula, mas os que fizeram isso utilizaram muito bem o recurso. As regras da atividade foram basicamente seguidas, com exceção de um aluno que se esqueceu de criar um título para sua história e de uma aluna que copiou uma tirinha já existente na internet, não criando, portanto, uma história inédita. Seguem, nas imagens 10, 11 e 12, algumas das tirinhas criadas pelos alunos.

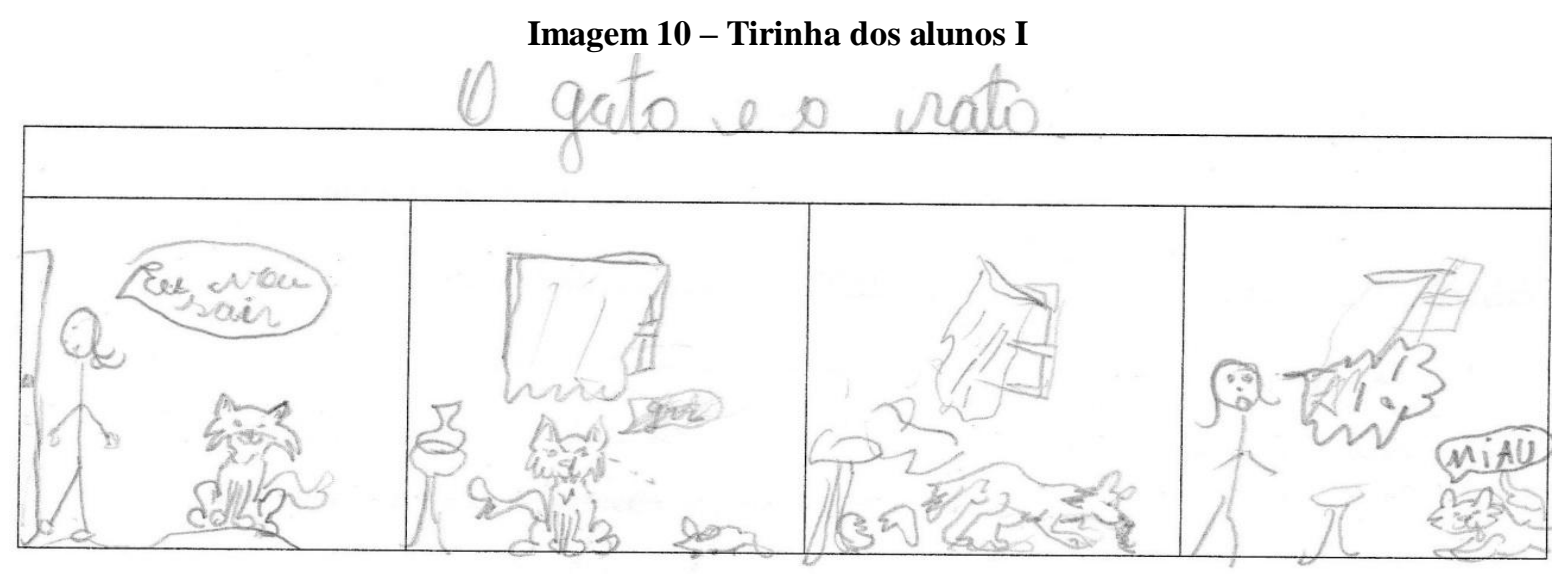

Fonte: Arquivos da autora. 


\section{Imagem 11 - Tirinha dos alunos II}

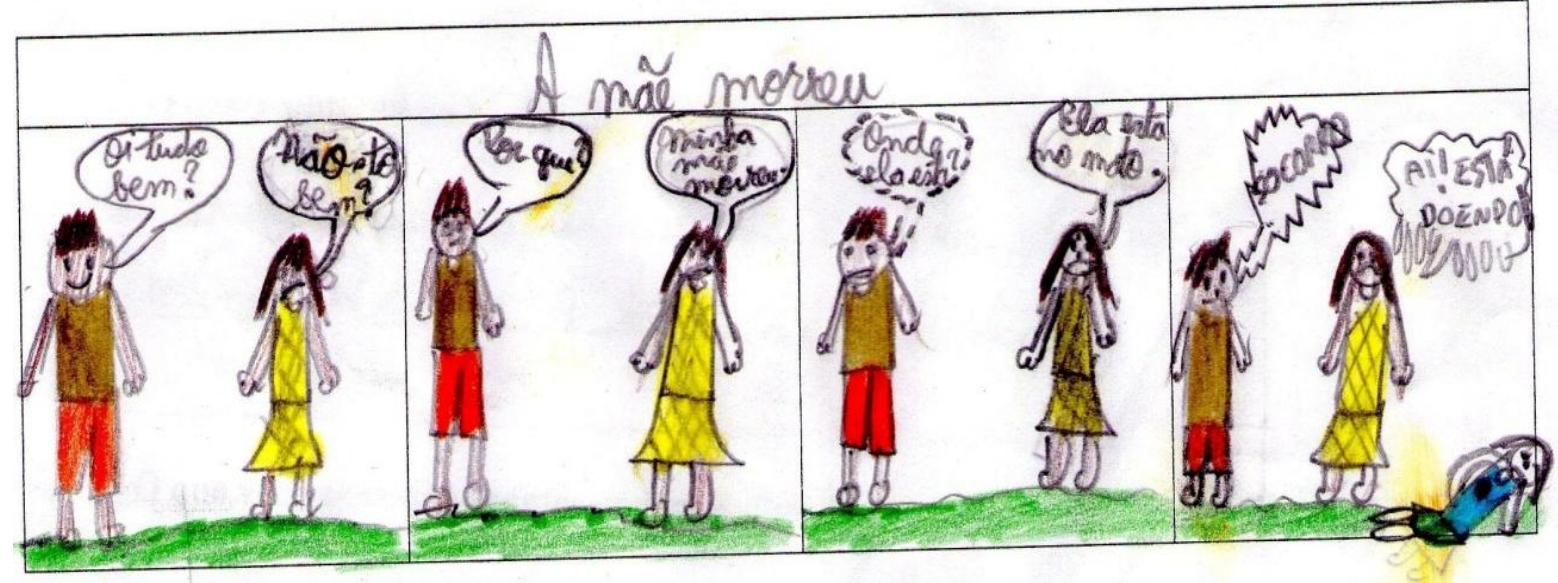

Fonte: Arquivos da autora.

Imagem 12 - Tirinha dos alunos III

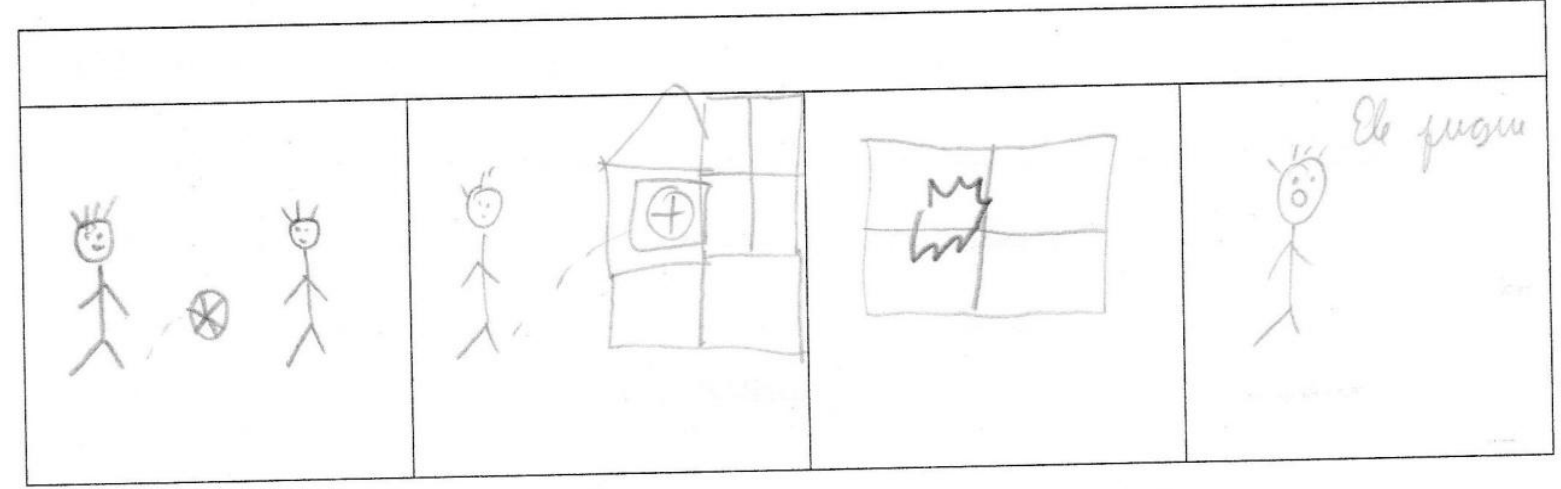

Fonte: Arquivos da autora.

Os alunos criadores das tirinhas apresentadas nas imagens 10 e 11 seguiram bem as instruções pedidas na atividade de produção, criando um título para as historinhas e utilizando diferentes tipos de balões para a representação da fala dos personagens (balão convencional, balão de grito, balão de sussurro e balão de choro), além de utilizarem bem o espaço para o desenvolvimento das histórias, que possuem início, meio e fim. Os alunos demonstraram utilizar bem a escrita do Português, apesar da omissão de alguns sinais de pontuação e de alguns erros ortográficos, e também de terem grande habilidade em desenhar. $\mathrm{O}$ aluno criador da tirinha apresentada na imagem 12 demonstra ter tido mais dificuldades na leitura do enunciado da atividade de produção e na compreensão de algumas características do gênero, já que não criou um título para a historinha e não representou a fala do personagem do último quadrinho dentro de um balão. 
Porém, percebe-se que a mensagem que ele quis passar através de sua tirinha é bem compreendida através de seus desenhos.

A interpretação e análise destas e de outras tirinhas criadas pelos alunos renderia várias colocações interessantes, tais como o uso do espaço, o tema escolhido, os recursos visuais empregados, porém esse não é o objetivo deste artigo. O que as tirinhas criadas pelos alunos evidenciam é que o uso da Libras bem como a adaptação dos materiais didáticos no ensino de Português para alunos surdos é essencial para o real aprendizado desses alunos. Segundo Albres (2010, p. 171), a elaboração das aulas e das atividades por parte do professor deve ser "desenvolvida mediante pesquisa de temas interessantes para os alunos, direcionando-se o ensino do léxico em cada unidade, com o objetivo de contemplar aspectos da gramática e atingir a produção e a compreensão da língua, ou seja, a comunicação".

Após a entrega das tirinhas finalizadas, foi confeccionado um livrinho com a coletânea de historinhas criadas pelos alunos, com todas as descrições (nome do autor, título da tirinha, nome da escola, dedicatória aos alunos, professores e funcionários, etc.) em Português e em datilologia, utilizando a fonte de Libras do programa Word. Os alunos ficaram muito surpresos no momento em que receberam seus livrinhos e demonstraram satisfação ao verem que suas historinhas também poderiam ser lidas pelos seus colegas.

\section{Considerações finais}

Através deste artigo pretendia-se defender a Educação Bilíngue como a melhor filosofia de ensino para alunos surdos. Para tanto, foi apresentada, inicialmente, a visão de alguns teóricos a respeito dos métodos de ensino que foram e ainda são utilizados nas salas de aula de alunos surdos. Como foi citado, o oralismo não dá conta de abarcar as especificidades dos alunos surdos, visto que impõe o uso de uma língua que não é a língua materna desses indivíduos, impedindo-os de se desenvolverem naturalmente em sua língua natural, a língua de sinais. A Comunicação Total, apesar de ter sido um pontapé inicial para o uso da língua de sinais nas salas de aula, também não proporciona um aprendizado natural, uma 
vez que utiliza sistemas artificiais, como o português sinalizado, por exemplo, que não apresenta completamente nem a estrutura da Libras, nem a estrutura do Português. Dessa forma, o bilinguismo se mostra como mais adequado para o contexto dos alunos surdos, já que, segundo Quadros (1997, p. 27), “considera a língua de sinais como língua natural e parte desse pressuposto para o ensino da língua escrita”.

Depois da apresentação das filosofias de ensino, foi abordada a grande dificuldade enfrentada pelos professores ao ensinarem o Português como segunda língua para seus alunos surdos, propondo algumas saídas que são sugeridas por Albres (2010). Por fim, foi apresentado um Projeto de Estágio com o gênero textual tirinha, que foi aplicado em uma escola especializada em Educação de Surdos, analisando os desafios que foram encontrados pela professora estagiária e discutindo os métodos utilizados por ela durante a aplicação da aula e as tarefas produzidas pelos alunos, confirmando a eficácia do uso da Libras, mesclado ao uso do português-porescrito, proposto pelos defensores da Educação Bilíngue.

A aplicação do Projeto de Estágio confirmou que o ensino de Português para alunos surdos é um grande desafio para os professores que não se sentem devidamente capacitados para desenvolverem tal tarefa. Com relação à leitura, interpretação e a produção de tirinhas, foi possível notar que o grande obstáculo para os alunos surdos é o uso da língua portuguesa escrita, uma vez que estes alunos não dominam suas estruturas sintáticas, já que sua língua natural é a Libras. Como se pôde notar, as atividades realizadas pelos alunos foram pouco exploradas, visto que há muitas outras questões que proporcionariam uma pesquisa muito extensa, que não era o objetivo deste artigo.

O que se pode concluir é que, apesar de a Educação Bilíngue ser um direito garantido por lei, ainda há muito que se fazer no Brasil, visto que não se deve apenas incluir o aluno surdo em uma sala de ouvintes, mas sim adaptar todo o contexto da escola, o que requer a contratação de professores devidamente capacitados, a presença do intérprete nas salas de aula e a adequação dos materiais didáticos e dos métodos de avaliação. Também se confirmou a hipótese de que os professores de Língua Portuguesa devem ser devidamente capacitados para oferecerem um melhor desenvolvimento cognitivo para seus alunos surdos, levando em consideração que o contexto de aprendizado destes alunos é diferente dos outros alunos que estão acostumados a ensinar, já que se deve levar em conta 
que os surdos possuem a língua espaço-visual como língua materna. Espera-se que este trabalho possa suscitar outros estudos na área da Educação de Surdos e ajudar de alguma forma os atuais e futuros professores de surdos, sejam eles de escolas regulares ou de escolas especiais.

Olh@res, Guarulhos, v. 2, n. 1, p. 345-372. Maio, 2014. 
Referências

ALBRES, Neiva de Aquino. Surdos e Inclusão Educacional. Rio de Janeiro: Arara Azul, 2010.

BERNARDINO, Elidéa Lúcia. Absurdo ou lógica? Os surdos e sua produção linguística. Belo Horizonte: Profetizando Vida, 2000.

BRASIL, Decreto $n^{\circ} \mathbf{5 . 6 2 6}$, que regulamenta a Lei $\mathrm{n}^{\circ} 10.436$, de 24 de abril de 2005, que dispõe sobre a Língua Brasileira de Sinais - Libras, e o art. 18 da Lei n ${ }^{\circ} 10.098$, de 19 de dezembro de 2000. Brasília: 2005. 11 p. Disponível em: << http://www.planalto.gov.br/ccivil_03/_ato20042006/2005/decreto/d5626.htm>>. Acesso em: 10 jun. 2013.

Lei $\mathbf{n}^{\circ}$ 10.436, que dispõe sobre a Língua Brasileira de Sinais - Libras e dá providências. Brasília: 2002. 1 p. Disponível em: <<http://www.planalto.gov.br/ ccivil_03/leis/2002/L10436.htm〉>. Acesso em: 10 jun. 2013.

BRITO, Luan Talles de Araújo; ELIAS, Solange da Silva. O trabalho com o subgênero tirinha: o que se fala e o que se cala. In: Semana de Letras: Linguagens e Entrechoques Culturais, n 6, 2011, Paraíba. Anais... Catolé do Rocha: Universidade Estadual da Paraíba, 2011, p. 1-11. Disponível em: << http://entrechoques.ccha.uepb.edu.br/2011/gt02/gt02T006.pdf >>. Acesso em: 10 jun. 2013.

GESSER, Audrei. Libras? Que língua é essa? São Paulo: Parábola, 2009.

LUCAS, Regiane. Protesto contra atual modelo do Mec de educação para os surdos. Portal Mara Gabrilli. 2013. Disponível em: $<<<$ http://www.maragabrilli.com.br/imprensa/428-protestocontra-atual-modelo-do-mec-de-educacao-para-surdos.html.〉>. Acesso em: 10 jun. 2013.

MOTERANI, Natália Gonçalves; MENEGASSI, Renilson José. O conteúdo temático no gênero discursivo tiras em quadrinhos. Acta Scientiarum. Language and Culture, Maringá, v. 32, n. 2, p. 225-232, 2010. Disponível em: << periodicos.uem.br/ojs/index.php/.../article/.../9536 >>. Acesso em: 10 jun. 2013.

A escrita do gênero discursivo tira em quadrinhos em uma sequência didática. In:

Encontro do Celsul, ${ }^{\circ}$ 9, 2010, Palhoça. Anais... Santa Catarina: Universidade do Sul de Santa Catarina, 2010, p. 1-9. Disponível em: <<

http://www.celsul.org.br/Encontros/09/artigos/Natalia\%20Moterani.pdf $>$. Acesso em: 10 jun. 2013.

POKER, Rosimar Bortolini. Texto 2: Abordagens de ensino na educação da pessoa com surdez. (Texto elaborado para uso no curso de Libras a distância da UNESP de Marília). Universidade Estadual Paulista, Marília, s.d. Disponível em: $<<$ http://www.marilia. unesp.br/Home/Extensao/Libras/mec_texto2.pdf >>. Acesso em: 10 jun. 2013.

PEREIRA, Maria Cristina da Cunha. Papel da língua de sinais na aquisição da escrita por estudantes surdos. In: LODI, Ana Claudia B. et al (Org.). Letramento e Minorias. Porto Alegre: Mediação, 2003. 
QUADROS, Ronice Müller de. Educação de surdos: a aquisição da linguagem. Porto Alegre: Artmed, 1997.

QUADROS, Ronice Müller de; KARNOPP, Lodenir Becker. Língua de Sinais Brasileira: estudos linguísticos. Porto Alegre: Artmed, 2004.

RODRIGUES, C. H. R. Situações de incompreensão vivenciad as por professor ouvinte e alunos surdos em sala de aula: processos interpretativos $\mathrm{e}$ oportunidades de aprendizagem. 2008. 239f. Dissertação (Mestrado em Educação e Linguagem). Faculdade de Educação, Universidade Federal de Minas Gerais, Belo Horizonte, 2008. Disponível em: << http://www.bibliotecadigital.ufmg.br/dspace/bitstream/handle/1843/FAEC-

85LMNK/rodrigues_c._h._disserta_o__2008.pdf?sequence=1 >. Acesso em: 10 jun. 2013.

SILVA, Alessandra Gomes da. A leitura de charges e tirinhas como recurso pedagógico na educação de jovens e adultos surdos. 2010. Disponível em: < http://alb.com.br/arquivomorto/portal/5seminario/PDFs_titulos/A_leitura_de_charges_e_tirinhas_como_recurso.pdf $>$. Acesso em: 28 abr. 2013.

VIEIRA, Patrícia Araújo; ARAÚJO, Vera Lúcia Santiago. Observações sobre a leitura da imagem em atividades com surdos na perspectiva de Kress e van Leewen. ReVel, v. 10, n. 19, 2012. Disponível em: << http://www.revel.inf.br/files/b2764d635a80770c527c8a0eadd72f43.pdf >. Acesso em: 10 jun. 2013.

VILELA, Genivalda Barbosa. Histórico da Educação do Surdo no Brasil. s.d.Disponível em: <<http://www.feneis.com.br/page/noticias_detalhe.asp?categ=1\&cod=623>>. Acesso em: 10 jun. 2013. 